\title{
Considerações sôbre telhados de edifícios
}

\author{
JUSTO MORETTI FILHO \\ Assistente da 6a. Cadeira - Engenharia Rural \\ Escola Superior de Agricultura "Luiz de Queiroz". \\ Universidade de S. Paulo - Piracicaba
}

\section{INDICE}

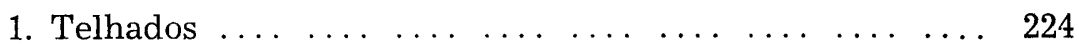

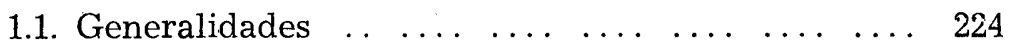

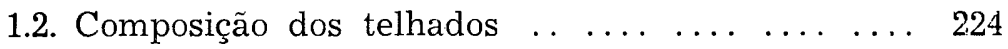

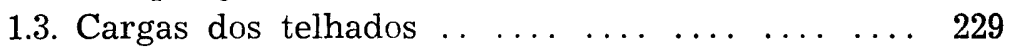

2. Cálculo das tesouras $\ldots \ldots \ldots \ldots \ldots$

2.1. Método de Cremona ou das figuras recíprocas 235

2.1.1. Regras para o traçado do diagrama de Cremona 236

2.2. Cálculo dos caibros $\ldots . \ldots . \ldots . \ldots . \ldots . \ldots .240$

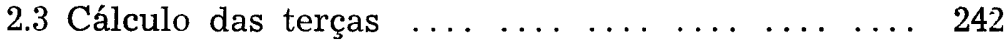

2.4. Cálculo da emenda de peças de madeira para o $\begin{array}{llllllllll}\text { arrochante } & . & \ldots & \ldots & \ldots & \ldots & \ldots & \ldots & \ldots & \ldots\end{array}$

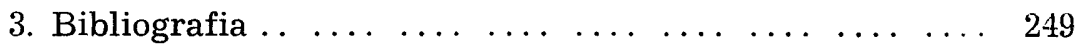

4. Projetos de tesouras de madeira (Peroba) ...... 250 


\section{TELHADOS}

\subsection{Generalidades :}

A cobertura dos edifícios se faz mediante a construção do "telhado", constituído geralmente de telhas que, além de cobrí-los, servem para protegê-los contra a ação dos agentes atmosféricos. Assim sendo, os telhados em sua parte externa assumem o aspecto de superfícies planas ou curvas. As primeiras, geralmente, são inclinadas em relação ao horizonte, segundo uma ou mais vertentes (ou "águas") nêste último caso, elas se interseccionam em vários pontos do telhado, correspondentes aos "espigões" e aos "rincões". Os "espigões" (ou divisores de água) são as partes em ângulos salientes que dividem, ou melhor, que distribuem a neve e a água das chuvas entre as vertentes; os "rincões" são as partes em ângulos reentrantes que recolhem e promovem a saída fácil dêsses agenles atmosféricos.

A forma do telhado é, em geral, consequência direta da planta do edifício; depende, porém, de vários fatôres : as condições climatéricas do lugar, os materiais empregados na cubertura e o estilo arquitetônico atribuido à construção.

A declividade do plano do telhado varia com a natureza do material de cobertura e com o clima do lugar. Uma declividade exagerada é prejudicial à armadura do telhado devido à ação dos ventos, assim como também pequenas declividades que não oferecem rápido escoamento das águas pluviais e das neves. Estas, quando armazenadas, aumentam a sobrecarga acidental dos telhados.

A telha comum de barro, "meio cano", pode ser empregada com declividades de 30 a $50 \%$ (1). Em declives muito fortes, estarão sujeitas a escorregamencos, inconveniente êste que poderá sèr evitado se as telhas forem amarradas. Declives suaves são inconvenientes às telhas de barro ou de materiais porosos e absorventes, porque as águas das chuvas não terão aí um escoamento rápido e, por isso, serão absorvidas em maior quantidade, por capilaridade, até às articulações das telhas, formando goteiras. Nêste caso, é aconselhável o uso de materiais metálicos ou impermeáveis à cobertura.

\subsection{Composição dos telhados:}

Os telhados são constituidos de três partes: a) armaduras principais que compreendem as tesouras com os respectivos contraventamentos; b) armaduras secundárias ou armação que 
é o conjunto de terças, caibros e ripas; c) cobertura ou revestimento (telhas, chapas, etc.).

a) A tesoura é considerada uma estrutura reticulada plana, em geral de forma triangular, indeformável ou formada por uma sucessão de triângulos, cujos lados se acham representados por peças que se denominam "barras" e seus vértices se chamam "nós". Consideram-se para efeito de cálculo as "barras" articuladas nos nós, que são indeformáveis e rígidos (6).

As tesouras são dispostas em planos verticais, tendo como apôio as paredes externas ou colunas do edifício, transmitindo a elas, através do apôio, todo o pêso do telhado mais as sobrecargas.

São vários os materiais empregados à construção das tesouras : concreto armado, ferro, aço e o mais comum é a madeira, principalmente usada para vãos pequenos. Em geral, as tesouras que se constroem para grandes vãos são destinadas aos telhados de indústrias, empregando-se nelas ferro, que, nêste caso, é o material mais indicado. $O$ ferro se presta, ainda, muito bem à construção de determinados tipos de armaduras, como por exemplo a "Polonceau", a "Inglesa" e outras que podem servir para vãos de 12 a $24 \mathrm{~m}$ ou mais. E' muito comum, todavia, encontrarmos, com vantagem à armadura, a associação de madeira e ferro, sendo êste representado por tôdas ou algumas barras da armadura que trabalham à tração, como por exemplo, os pendurais.

Há muitos tipos de tesouras de ferro e de madeira; a fim de fazermos um estudo das partes que compõem uma tesoura, com a respectiva nomenclatura, vamos, porém, estabelecer a comparação entre dois tipos apenas, aliás, um bem diverso do outro, quanto ao trabalho das barras. As barras que constituem uma tesoura estão sujeitas a esforços subordinados à atuação das "fôrças externas", isto é, pêso da cobertura, pêso próprio da tesoura, mais o da armação ( cargas permanentes), pressão da neve e do vento (cargas acidentais) e das reações ou fôrças que suportam a tesoura. Estas se localizam nos apôios que são as paredes, colunas, etc., dos edifícios. Quando as pressões transmitidas à tesoura são ocasionadas por fôrças externas verticais, em correspondência as reações também serão verticais. $O$ pêso da coberta, por exemplo, considera-se distribuido nas tesouras, exercendo pressão vertical nos nós (ponto de intersecção das direções dos esforços de duas ou mais barras) e, naturalmente, as reações atuarão verticalmente pe- 
las extremidades da tesoura, pois trata-se do equilíbrio de um sistema de fôrças paralelas de sentidos opostos. Quando as forças externas mais as sobrecargas atuam sôbre uma tesoura qualquer, devemos admitir que se desenvolvem duas espécies de tensões entre as diversas barras: tração e compressão. Como já dissemos a princípio, a armadura é formada de um conjunto de barras que se articulam nos nós, formando triângulos. Assim, é fácil de prever-se que, ao defrontarmos com a armadura colocada em sua posição definitiva no edifício, isto é, em plano vertical, vamos notar que nela se distinguem barras horizontais, verticais e inclinadas. Na Fig. 1 ( $a$ e $b$ ) temos representadas esquemàticamente os dois tipos propostos de tesouras : Howe ou inglesa e Pratt. Em ambas as tesouras, o triângulo externo ABC é formado pela "corda ou banzo inferior" $\mathrm{AC}$ e pela "corda ou banzo superior $\mathrm{ABC}$, isto é, o conjunto das duas barras inclinadas $\mathrm{AB}$ e $\mathrm{BC}$ que se denominam "asnas" ou "empenas" ou "pernas". Note-se que se considerássemos $\mathrm{AB}$ ou $\mathrm{BC}$ e $\mathrm{AC}$ como se fossem uma única barra, o que de fato ocorre na realidade, a tesoura não seria uma estrutura totalmente articulada, como se considera para o cálculo, mas sim uma estrutura semi-articulada. A corda inferior recebe as denominações "arrochante", "tirante", "estirante", "extensor" e "tensor".

(a)

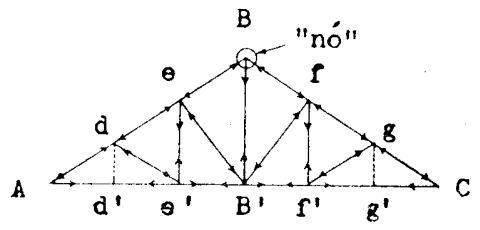

TESOURA HOWB OU INGLESA (b)

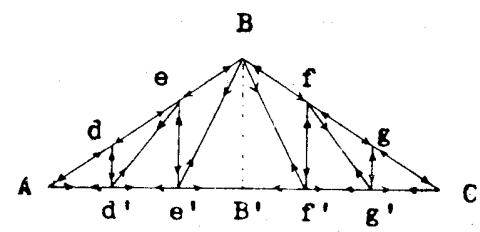

TESOURA PKATT

- FIG. 1 -

E' uma barra que sempre trabalha à tração, enquanto as “asnas" sempre trabalham à compressão.

Na Fig. $1(a)$ as barras verticais $d d^{\prime}$, e e', $B B^{\prime}$ etc. são tracionadas e recebem o nome de "pendurais" para diferençar dos "montantes" que trabalham comprimidos, isto é, as mesmas barras verticais da tesoura da Fig. 1 (b). Em $(a), B B^{\prime}=$ "pendural principal" ou "pé direito" da tesoura. Em (b), $B B^{\prime}$ seria "montante principal", correspondente ao também "pé 
direito"; como essa barra alí colocada seria, porém, completamente inutil à estrutura, não há razão dela existir.

As peças ou barras inclinadas internas da Fig. 1 (a) como

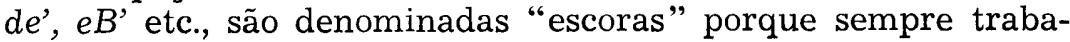
lham comprimidas, enquanto as barras correspondentes na Fig. $1(b)$, d'e, $e^{\prime} B$, etc., que sempre trabalham tracionadas, não têm denominação especial. Alguns costumam chamá-las de "diagonais" para distinguí-las das escoras. Também a barra $e B^{\prime}$ ou $f B^{\prime}$ da Fig. 1 (a) é chamada por muitos de "mão francesa".

Pela comparação dos dois tipos citados de tesouras, concluímos que os tirantes (ou arrochantes) e os pendurais são barras que trabalham invariàvelmente à tração enquanto as asnas, escoras e montantes, trabalham sempre à compressão.

Para o estudo de qualquer outro tipo de tesoura, diferente dos acima apontados, devemos, em primeiro lugar, verificar de que maneira trabalham as diversas barras, se à tração ou se à compressão. Para as barras internas inclinadas, qualificaremos diagonal ou escora se elas trabalharem à tração ou compressão, respectivamente. Se as barras verticais trabalharem comprimidas, elas serão montantes, caso contrário, pendurais.

As intersecções de duas ou mais barras constituirão os "nós". Reservamos a denominação de "painel" à distância horizontal entre dois nós consecutivos. Por exemplo, as tesouras que representamos na Fig. 1 são de 6 paineis.

"Vão" de uma tesoura é a distância $L$ entre os nós extremos ou de apôio.

"Inclinação" ou "ponto" da tesoura é a relação H/L entre a "altura" ou "pé direito" e o vão. O ponto varia entre os limites de $1 / 2$ e $1 / 6$. Em geral, adota-se a média dêsses denominadores, isto é, $1 / 4$, o que quer dizer que as asnas formam com o horizonte um ângulo de $26^{\circ} 30^{\prime}$ aproximadamente, ou, então, que se inclinam à razão de $50 \%$ em relação ao horizonte.

A tesoura é uma estrutura reticular triângulada isostática, isto é, formada do conjunto de triângulos elementares, os quais são indeformáveis e estàticamente determinados. Do triângulo, figura fundamental da Estática Gráfica, tiramos a seguinte lei :

$$
\mathrm{b}=2 \mathrm{n}-3
$$

sendo

$$
\begin{aligned}
& \mathrm{n}=\text { número de vértices ou nós } \\
& \mathrm{b}=\text { número de lados ou barras }
\end{aligned}
$$


que significa a condição "sine qua non" para que uma estrutura seja determinada estàticamente, ou melhor, que o númer: de barras deve ser igual a duas vezes o número de nós menos três. Quando $b<2 n-3$, trata-se de um sistema deformável e, portanto, sem estabilidade; se $b>2 n-3$, tem-se então um sistema superabundante, indeterminado estàticamente (ou hiperestático).

O afastamento entre tesouras varia de conformidad o vão e o tipo de cobertura. Para tesouras de madeira, êsse afastamento deve variar de 2,5 a $5 \mathrm{~m}$ de eixo a eixo; quanto maior o vão, menor é o afastamento. Para tesouras metálicas de grandes. vãos, o espaçamento pode atingir $8 \mathrm{~m}$.

Os contraventamentos são formados por tirantes em cru para pequenos afastamentos ou por um sistema qualquer de treliças, ligando as tesouras de modo a formar um conjunto rígido.

A função do contraventamento é importantíssima, infiu. do sobremaneira quanto à estabilidade das tesouras, pois, por seu intermédio, os telhados resistem à ação lateral do vento.

b) A armadura secundária ou armação do telhado compreende o conjunto de peças que se apoiam sôbre as tesouras, a fim de receber a cobertura e transmitir a carga desta e mais o seu pêso próprio às tesouras. A armadura compõe-se de terças, caibros e ripas.

Terças: são as vigotas ou peças tt' (Fig. 2) que se apoiam sôbre as tesouras (diretamente nas asnas), e devem ser sempre pregadas nos nós, a fim de não flexionar as asnas. Reservase o nome de cumieira (cc') à terça que se situa sôbre os nós centrais das tesouras, que, por se achar no cume do telhado re-

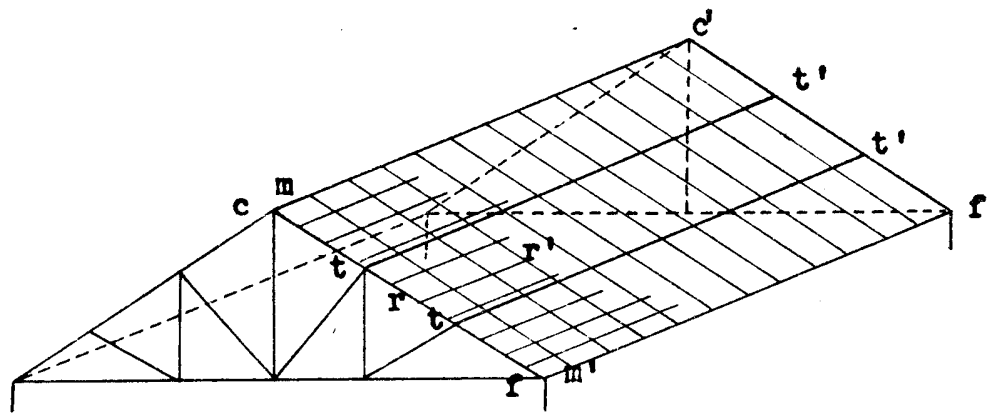

Fig. 2 
cebeu aquela denominação. Em contraposição, a terça mais baixa, que margeia a linha das calhas, recebe o nome de contrafrechal (ff'). As terças têm um espaçamento de $1 \mathrm{~m}$ a $3 \mathrm{~m}$ e trabalham como vigas carregadas com cargas concentradas de mesmo valor e equidistantes, transmitidas pelos caibros. Todavia, elas são calculadas como se a carga fosse uniformemente distribuida em todo o seu comprimento (distância entre tesouras).

Caibros : são as peças $m m^{\prime}$ (Fig. 2) geralmente de madeira mesmo nas estruturas metálicas, que se apoiam diretamente sôbre as terças e são dispostas e pregadas normalmente às mesmas. $O$ afastamento varia de 40 a $60 \mathrm{~cm}$, mais comumente $50 \mathrm{~cm}$, dependendo do material de cobertura. Para telhas de cimento amianto, êsse espaçamento pode atingir $2 \mathrm{~m}$ ou mais, conforme as dimensões usuais e próprias para cada tipo de telha encontrado no comércio, não havendo necessidade de ripas.

Ripas : são as peças rr' (F'ig. 2) de madeira, pregadas normalmente aos caibros, portanto, na direção das terças e que recebem o material de cobertura. $O$ afastamento das ripas depende do tamanho das telhas; para telhas curvas de barro (meio cano), costuma ser de $20 \mathrm{~cm}$ e para telhas francesas, de $34 \mathrm{~cm}$. As dimensões mais comuns para a seção das ripas são $1 \times 5 \mathrm{~cm}$ ou $1,5, \times 5 \mathrm{~cm}$.

c) A cobertura ou revestimento dos telhados se faz com materiais os mais diversos. As mais comuns são as telhas de barro as quais podem se apresentar curvas (meio cano ou paulista), chatas ou planas (francesa ou tipo Marselha). Temos também as telhas de cimento, de ardósia, chapas de ferro galvanizadas, onduladas e de vidro.

\subsection{Cargas dos telhados:}

Para o cálculo de uma tesoura qualquer, devemos considerar duas espécies de cargas : carga permanente e carga acidental. Como o nome já indica, a carga permanente consta do pêso próprio da tesoura, do pêso da armação e do pêso da cobertura. Se houver fôrro, o pêso dêste deve ser calculado e incluido nesta carga. A carga acidental é constituida da pressão do vento, do pêso de operários sôbre o telhado e, também, conforme o lugar, do pêso da neve.

Tôdas estas cargas se concentram nos nós da tesoura por meio das terças e os nós transmitem essas fôrças (cargas) às barras, originando nelas as tensões de tração ou de compressão. 
a) Carga permanente : O pêso próprio das tesouras é também considerado como carga vertical concentrada nos nós. Êste pêso depende de vários fatôres : do material (ferro ou madeira), do tipo, do vão, da altura e do espaçamento entre tesouras.

O pêso próprio é determinado aproximadamente de diversas maneiras. Uma delas seria atribuirmos à tesoura um pêso aproximado, escolhendo arbitràriamente as dimensões estimativas de cada barra e calculando o pêso de cada uma delas, de acôrdo com o material empregado. A maneira mais cômoda seria compararmos a tesoura em questão com outras semelhantes já construidas e calculadas, repetindo para ela o pêso próprio conhecido de uma destas.

$O$ êrro que se comete em determinar o pêso próprio das tesouras é insignificante diante dos esforços máximos que são causados pela pressão do vento e pelo pêso da cobertura..

Podemos também recorrer ao emprêgo de fórmulas empíricas à avaliação do pêso próprio, porém muitas vezes elas chegam a resultados incertos.

O pêso das terças é calculado separadamente e deve ser somado ao pêso da cobertura. $O$ pêso do conjunto também se considera como carga vertical concentrada nos nós.

O pêso da cobertura consta do pêso das telhas, variável conforme os tipos e espécies empregadas, e do pêso dos caibros e ripas. Por exemplo, para telhas francesas temos: pêso médio de uma telha $=2,5 \mathrm{Kg}$; o número de telhas por $\mathrm{m}^{2}=15 \mathrm{a}$ 16 , usando-se ripas de $1,5 \times 5 \mathrm{~cm}$ e caibros de $5 \times 7 \mathrm{~cm}$, distantes de $0,5 \mathrm{~m}$, para espaçamento entre terças $=2 \mathrm{~m}$. O pêso total por $\mathrm{m}^{2}$ de cobertura com essas telhas será:

Telhas

Caibros e ripas
$40 \mathrm{Kg} / \mathrm{m}^{2}$

$12 \mathrm{Kg} / \mathrm{m}^{2}$

Embebição de água de chuva ( $\pm 20 \%$ do pêso de telhas)

Total
$8 \mathrm{Kg} / \mathrm{m}^{2}$

$60 \mathrm{Kg} / \mathrm{m}^{2}$

O pêso por $\mathrm{m}^{2}$ para as telhas curvas de barro é ainda superior ao de telhas planas. Pêso médio de uma telha (meio cano) $=2,8$ a $3,00 \mathrm{Kg}$; número de telhas por $\mathrm{m}^{2}=20$ a 22 . Temos, pois, para uma cobertura com telhas curvas: 


\begin{tabular}{lcl}
$\begin{array}{l}\text { ripas e caibros } \\
\text { telhas }\end{array}$ & $10 \mathrm{Kg} / \mathrm{m}^{2}$ & (incl. a argamassa) \\
umidade & $65 \mathrm{Kg} / \mathrm{m}^{2}$ & \\
\multicolumn{1}{c}{ Total } & $15 \mathrm{Kg} / \mathrm{m}^{2}$ & $\begin{array}{l}( \pm 25 \% \text {, no max., do pêso } \\
\text { das telhas })\end{array}$
\end{tabular}

No telhado de um edifício qualquer, que contenha várias tesouras de vão $L$ que obedeçam a um espaçamento $e$, cada tesoura irá suportar, além do seu pêso próprio, a carga equivalente à área que se obtem multiplicando o vão $L$ pelo espaçamento e. Na Fig. 3, acha-se representado em planta o telhado de um edifício, com três tesouras $T T^{\prime}$, sendo as terças $t t^{\prime}, c c^{\prime}$ (cumieira) e cf cf' (contrafrechal). A tesoura central, por exemplo, absorve do telhado uma carga que corresponde à área do retângulo mnop, onde se tomou $\mathrm{Tm}=\mathrm{T} n=$ To $=$ $=\mathrm{T}^{\prime} \mathrm{p}=\mathrm{a}$ metade do espaçamento $e$ das tesouras. E' óbvio, pois, que $m o=n p=e$. Logo, a área do referido retângulo será igual ao produto $\mathrm{L} \times \mathrm{e}$.

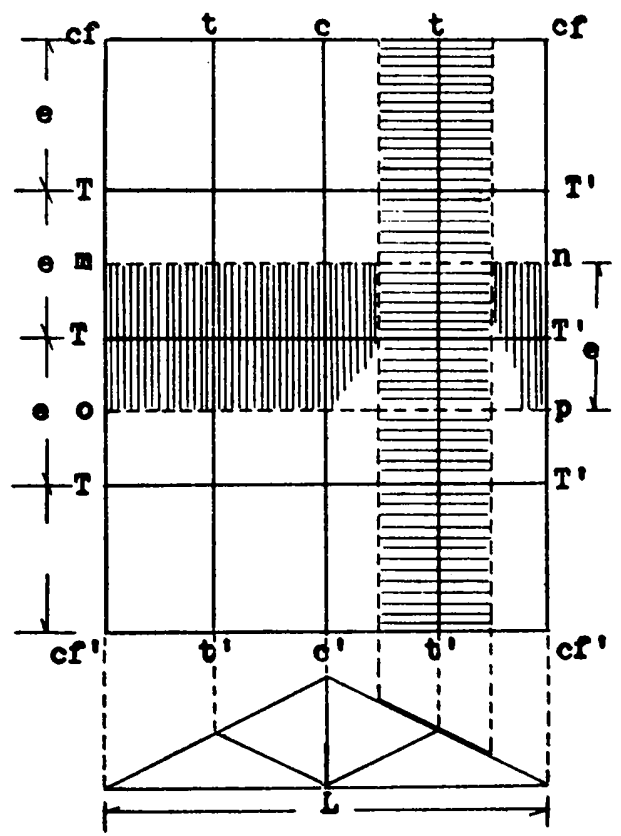

Fig. 3 
b) Carga acidental: As cargas acidentais mais importantes (ou perigosas) para nós, são as cargas oblíquas devidas à pressão do vento que se exerce normalmente à superfície dos telhados. Para os países frios, então, além da pressão do vento se deve levar em conta o pêso da neve (carga vertical) acumulada sôbre o telhado.

A pressão do vento provoca tensões nas barras da tesoura, as quais devem ser pesquisadas, supondo o vento atuando à esquerda ou à direita da armadura, uma vez que é impossível êle atuar nos dois sentidos.

As tensões máximas são somadas respectivamente às tensões em cada barra, originadas pelas cargas verticais, obtendo-se, assim, a tensão total correspondente a cada barra, da qual nos utilizaremos para o cálculo da estrutura.

A pressão do vento é função de vários elementos: da sua própria velocidade e direção, da natureza, forma e posição (inclinação) da superfície sôbre a qual êle atua.

Segundo as teorias modernas a ação do vento se compõe de uma pressão sôbre a superfície inclinada do telhado, na qual êle incide e de uma contrapressão, aspiração ou sucção (10) sôbre a superfície a sotavento. As experiências têm demonstrado que a aspiração, se não é equivalente, pode atingir um valor três vezes superior à pressão. Em virtude dessas observações, pois, a ação conjunta da pressão mais a aspiração deve ser ponderada para o estudo correto da ação do vento sôbre os telhados.

Nos telhados planos, o vento poderá incidir contra a superfície inclinada daqueles, segundo duas maneiras diversas:

1a.) $O$ caso mais geral é considerar-se o vento $P$ atuando na direção horizontal; o ângulo de incidência será o mesmo ângulo $\alpha$ de inclinação do telhado. A pressão $P$ quando encontra a superfície inclinada do telhado se decompõe, segundo $P n$, normal ao plano inclinado, e $P a$, tangencial ao mesmo plano. Esta componente apenas se atrita e resvala ao longo da superfície do telhado.

A componente normal é a única que vai exercer pressão sôbre o telhado, sendo fàcilmente obtida pela expressão

$$
\mathrm{Pn}=\mathrm{P} \cdot \operatorname{sen} \varkappa
$$

As velocidades de 30 e $45 \mathrm{~m} / \mathrm{seg}$, tidas como máximas (correspondentes a tempestades e furacões violentos, respectivamente) obtem-se uma ação do vento horizontal de $p=60$ 
a $150 \mathrm{Kg} / \mathrm{m}^{2}$ de superfície normal à sua direção, ação essa na qual se computou a pressão mais aspiração.

E' frequente, também, transformar-se a pressão normal $P n$ do vento na pressão vertical $\mathrm{Pv}$ a qual é somada às cargas verticais permanentes das tesouras, de sorte que a armadura é solucionada com um cálculo apenas, o que vem facilitar o cálculo. Para essa componente vertical teriamos:

$$
\mathrm{Pv}=\mathrm{Pn} \cdot \cos \alpha=\mathrm{P} \operatorname{sen} \alpha \cdot \cos \alpha=\mathrm{P} \frac{\operatorname{sen} 2 \alpha}{2}
$$

assim como para a componente horizontal,

$$
\mathrm{Ph}=\mathrm{Pn} \cdot \operatorname{sen} \alpha=\mathrm{P} \cdot \operatorname{sen}^{2} \alpha
$$

Podemos, entretanto, para efeito e facilidade de cálculo tixar essa pressão vertical $\mathrm{Pv}$ nos limites $70-100 \mathrm{Kg} / \mathrm{m}^{2}$ que correspondem às velocidades máximas dos ventos, isto é, tempestades violentas e furacões.

2a.) E' hipótese muito admitida que a direção do vento forme um ângulo de $10^{\circ}$ com a horizontal. Nessas condições, teríamos para a pressão normal,

$$
\mathrm{Pn}=\mathrm{P} \cdot \operatorname{sen}\left(\dot{\alpha}+10^{\circ}\right)
$$

Pela decomposição dessa pressão resulta :

$$
\mathrm{Pv}=\mathrm{Pn} \cdot \cos \alpha=\mathrm{P} \operatorname{sen}\left(\alpha+10^{\circ}\right) \cdot \cos \alpha,
$$

correspondente à pressão vertical.

\section{CALCULO DAS TESOURAS}

Calcula-se uma tesoura, determinando-se antes, analítica ou gràficamente, os esforços aos quais se acham submetidas as diversas barras ou peças que compõem essa estrutura, para depois proceder-se ao cálculo pròpriamente dito, isto é, ao dimensionamento das peças, pela determinação das suas seç̧ões transversais.

A marcha geral para o cálculo de uma tesoura compreende : 
a) determinação da carga em cada nó, valendo-se do conhecimento prévio das cargas, permanentes ou acidentais;

b) determinação das reações nos apôios;

c) determinação das fôrças internas de compressão e tração desenvolvidas em cada peça ou barra;

d) dimensionamento, de acôrdo com os esforços a que se acham submetidas as barras e trabalho unitário admissível para o material a ser empregado na construção da tesoura.

Os itens a) e b) vamos exemplificar com o exemplo da Fig. 4 onde representamos uma tesoura com $12 \mathrm{~m}$ de vão, ponto $1 / 4$, espaçamento $3 \mathrm{~m}$.

Carga total: $150 \mathrm{Kg} / \mathrm{m}^{2}$

(projeção de telhado)
Vento $=70 \mathrm{Kg} / \mathrm{m}^{2} \quad$ (componente vertical)

Telhas $=50 \mathrm{Kg} / \mathrm{m}^{2}$

Pêso próprio $=30 \mathrm{Kg} / \mathrm{m}^{2}$

Tensão da madeira a ser empregada: $\sigma=70 \mathrm{Kg} / \mathrm{cm}^{2}$ (Peroba)

$$
\text { Comprimento da asna }=\sqrt{\overline{6,0}^{2}+\overline{3,0}}{ }^{2}=6,75 \mathrm{~m}
$$

Carga total sôbre a tesoura :

$$
12 \mathrm{~m} \times 3 \mathrm{~m} \times 150 \mathrm{Kg} / \mathrm{m}^{2}=5.400 \mathrm{Kg}
$$

Esta carga se considera repartida igualmente pelos 6 pai5.400

neis da tesoura, ou seja, $\frac{}{6}=900 \mathrm{Kg}$ para cada painel. Em cada painel, a carga correspondente se divide ao meio e as metades serão concentradas nos nós. Por conseguinte, teremos as cargas por nó :

$$
\mathrm{BC}=\mathrm{CD}=\mathrm{DE}=\mathrm{EF}=\mathrm{FG}=900 \mathrm{Kg}
$$

e para os dois nós extremos (os dos apôios) :

$$
\mathrm{AB}=\mathrm{GH}=450 \mathrm{Kg} \text {. }
$$

A tesoura é simétrica às cargas e, então, as reações se determinam diretamente : 


$$
\mathrm{R} 1=\mathrm{R} 2=\frac{5.400}{2}=2.700 \mathrm{Kg} .
$$

Conhecidas as reações, os esforços internos das barras provenientes das fôrças externas que atuam nos nós da tesoura podem ser determinados por vários processos, uns gráficos, outros analíticos, como por exemplo o de "Ritter". Dos gráficos, destacam-se os métodos de "Cremona", "Culmann" e "Ritter". Vamos nos cingir apenas ao método de "Cremona".

\subsection{Método de Cremona ou das figuras recíprocas:}

$\mathrm{O}$ método de Cremona tem por finalidade a determinação dos esforços internos de qualquer estrutura indeformável e triângular (4).

Denomina-se "Cremona" de uma tesoura a uma sucessão de polígonos de fôrça (ou vetoriais) fechados, cada um dos quais corresponde ao equilíbrio de um nó.

(a)

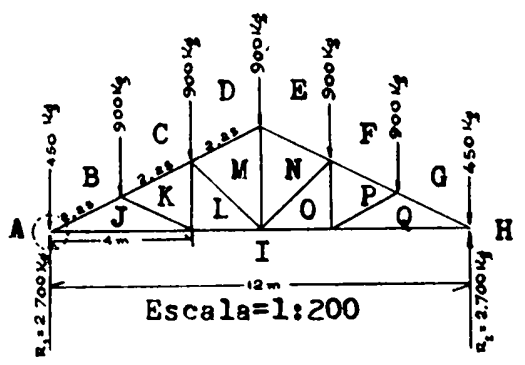

(b)

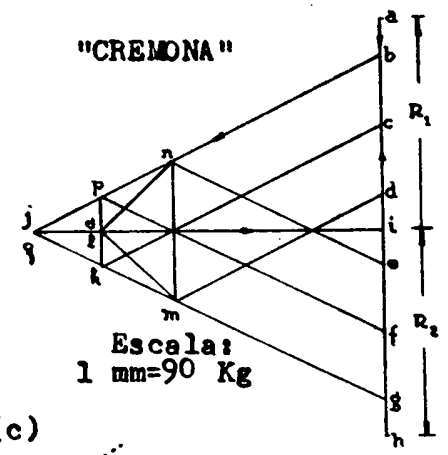

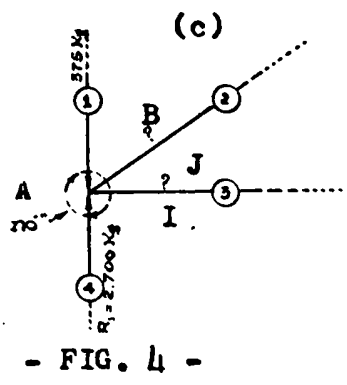


Se separarmos um nó qualquer, o primeiro, por exemplo, do apôio da esquerda da tesoura da Fig. 4 e substituirmos as tensões das barras que concorrem nèste nó, por fôrças externas equivalentes, será necessário que estas formem um sistema em equilíbrio, isto é, a elas deverá corresponder um polígono de fôrças fechado abjia. Ėste é uma figura recíproca da anterior e tem a propriedade de nos fornecer a grandeza e sentido das fôrças que atuam nas barras 2 e 3 (Fig. 4) (c) até então desconhecidas. $\mathrm{Na}$ barra 2, o esfôrço é de compressão pois, pelo sentido indicado pela seta, vemos que o mesmo comprime, ou melhor, tende a empurrar o nó em questão. Na barra 3 dáse justamente o inverso; o esfôrço é de tração porque tende a puxar o referido nó.

Podemos, pelo exposto, tirar as leis fundamentais da "figura recíproca". A um sistema de fôrças concorrentes nos nós, corresponde, no Cremona, um vetorial fechado, isto é, um poligono de fôrças de lados em número correspondente ao número de fôrças e vice-versa : todo polígono de $n$ fôrças no Cremona, corresponde ao seu recíproco de $n$ fôrças concorrentes no nó representado no esquema de fôrças. Nêsse esquema, vemos que os nós contíguos têm uma barra comum; consequentemente, os vetoriais correlativos terão um lado comum.

O essencial é que em cada nó tenhamos sempre, no máximo, duas barras desconhecidas. Todo diagrama de fôrças correspondente ao Cremona deve fechar com exatidão.

\subsubsection{Regras para o traçado do diagrama de Cremona:}

O Cremona, em última análise, se compõe de duas partes: o polígono das fôrças externas e os vetores dos esforços internos das barras que constituem a estrutura (as barras externas de contôrno ou cordas, superior e inferior e as barras internas).

Para o traçado do Cremona podemos observar as seguintes regras :

a) Uma vez achadas tôdas as reações traça-se, inicialmente, em escala conveniente, o polígono fechado das fôrças externas, tal como fizemos à Fig. 4. Por questão de comodidade e também de ordem, é conveniente adotar-se sempre um método na construção do referido polígono, como, por exemplo, ha. bituar-se a dispôr as fôrças externas na ordem em que elas se apresentam, à medida que formos, com os olhos, examinando o desenho da estrutura, no sentido da esquerda para a direita. O sentido é arbitrário, a critério de cada um. 
No caso da Fig. 4, sôbre uma linha vertical, paralela à direção das fôrças que representam a carga total disiribuida pelos diversos nós da tesoura, tomamos, na escala adotada, as cargas $\mathrm{AB}, \mathrm{BC}, \mathrm{CD}, \mathrm{DE}, \mathrm{EF}, \mathrm{GH}$ (notação de Bow para fôrças), representando-as pelas letras minúsculas correspondentes. Os segmentos que representam as reações direita e esquerda, serão $h i$ e $i a$, respectivamente, isto é, iguais à metade de $a h$, atuando em sentido opusto ao das cargas, de baixo para cima. A essa linha vertical, assim traçada, dá-se o nome de "linha de carga".

b) Inicia-se, agora, o diagrama dos esforços ou polígono de Cremona. Começamos pelo nó do apôio esquerdo onde se acham duas fôrças conhecidas (a reação $R 1=2.700 \mathrm{Kg}$ e a carga $\mathrm{AB}=450 \mathrm{Kg}$ ) e ouiras duas desconhecidas (os esforços internos ou tensões das barras BJ e JI).

Do ponto $b$ da linha de cargas (Fig. 4) tira-se uma paralela a BJ e de $i$ uma horizontal, isto é, uma paralela a JI. Estas duas linhas se interseccionam em $j$, até então desconhecido; bj e $j i$, transportados à escala de fôrças dão os valores dos esforços respectivos procurados.

A natureza dêstes esforços se conhece observando a ordem de sucessão das letras que se situam no nó em questão do diagrama (desenho auxiliar indispensável) da tesoura. Aqui também adotamos sempre o mesmo critério para todos os nós, isto é, elegemos o sentido do movimento dos ponteiros do relógio à sucessão das letras em tôrno de cada nó considerado, iniciando pela primeira fôrça conhecida. Por exemplo, na Fig. 4 (a), devemos lêr: $A B, B J, J I, I A$, para o nó do apôio esquerdo. Em consequência, na Fig. 4 (b) $a b, b j, j i$, ia são fôrças várias, que atuam de $a$ para $b$, de $b$ para $j$, de $j$ para $i$ e de $i$ para $a$, respectivamente, conforme as indicações que fizemos com as setas.

Estes sentidos são transportados para o diagrama da tesoura, com respeito ao nó que está sendo estudado. Assim o esfôrço em BJ é dirigido para o nó, como se fôsse empurrá-lo; inversamente, em JI, o esforço se afasta do nó, como se o puxasse. O primeiro é um esfôrço de compressão e o segundo, de tração.

Passamos ao nó seguinte: $\mathrm{BCKJ}$ e procedemos de maneira idêntica à do nó anterior. Do ponto $c$ traçamos uma paralela a $\mathrm{CK}$ e do ponto $j$, uma paralela a $\mathrm{KJ}$ que se interseccionam no ponto $k$, fornecendo os esforços $c k$ e $k j$. Os sentidos dos esforços são tirados da ordem de sucessão das lêtras em 
volta do nó considerado: $\mathrm{CK}, \mathrm{KJ}, \mathrm{JB}$, os quais, representados cada qual por uma seta, são transportados para o diagrama da tesoura. Nêste nó, vemos que todos os esforços se dirigem para êle e que, portanto, são de compressão.

Procedendo-se da mesma forma para os demais nós da tesoura, completamos o diagrama dos esforços.

Quando a tesoura é simétrica, em relação à carga permanente distribuida entre os nós, o diagrama dos esforços também o será de sorte que, nêste caso, é bastante determinarmos os esforços das barras de um lado apenas da tesoura.

Os segmentos de reta $b j, c k, d m, k j$, etc. (Fig. 4, b) do diagrama de Cremona, convertidos à escala adotada, corresponderão aos valores numéricos dos esforços internos procurados.

A seção transversal $S$ de uma barra submetida a um esfôrço $P$ de tração será calculada pela expressão

$$
\mathrm{P}=\sigma . \mathrm{S}(\mathrm{I}) \text { donde }, \mathrm{S}=\frac{\mathrm{P}}{\sigma}=\frac{\mathrm{Kg}}{\mathrm{Kg} / \mathrm{cm}^{2}}=\mathrm{cm}^{2} \text {. }
$$

ou seja, dividindo o esfôrço $P$ pelo esfôrço médio unitário ou coeficiente de trabalho $\sigma$ do material que constitui a barra.

Essa mesma expressão será também aplicada dirètamente aos esforços de compressão, porém quando se trate de barras trabalhando como colunas curtas. Devemos, pois, sempre verificar a relação de esbelteza .

$\frac{\mathrm{l}}{\mathrm{d}}=\frac{\text { comprimento da barra }}{\text { menor dimensão da seção transversal }}$

para os limites

$$
\begin{gathered}
\frac{\mathrm{l}}{\mathrm{d}}>11 \quad \text { (colunas longas) } \\
\frac{\mathrm{l}}{\mathrm{d}}<11 \quad \text { (colunas curtas) }
\end{gathered}
$$

Para as peças longas empregaremos a fórmula 


$\mathrm{P}=\sigma^{\prime} \cdot \mathrm{S}$, (II) na qual $\quad \sigma^{\prime}=\sigma\left(1-\frac{\mathrm{l}}{80 \mathrm{~d}}\right)$

fórmula de Gordon, também conhecida, como fórmula dos madeireiros americanos (8).

As fórmulas de Euler e de Rankine também têm grande aplicação ao cálculo das seções das peças. Todavia, optamos pela fórmula de Gordon que é muito cômoda quanto à sua aplicação e porque chega a resultados bastante satisfatórios.

Os valôres dos esforços achados no "Cremona" da Fig. 4 para cada barra da tesoura podem ser condensados em $u$ quadro de esforços auxiliar.

Para exemplificar, consideraremos aquí apenas duas barras.

\begin{tabular}{|c|c|c|c|c|c|}
\hline \multirow[b]{2}{*}{ B A R R A } & \multirow{2}{*}{$\underset{(m)}{\text { Comprimento }}$} & \multicolumn{2}{|c|}{ ESFORÇOS } & \multirow{2}{*}{ Socāo (cm2) } & \multirow{2}{*}{ Bitola (cm) } \\
\hline & & $\begin{array}{c}\text { Comprossāo } \\
(\mathrm{Kg})\end{array}$ & $\begin{array}{c}\text { Traçào } \\
(\mathrm{Kg})\end{array}$ & & \\
\hline JI & 4,00 & - & 4.500 & 64 & $16 \times 8$ \\
\hline BJ & 2,25 & 5,040 & - & 112 & $16 \times 8$ \\
\hline
\end{tabular}

Sendo a tensão da peroba $\sigma=70 \mathrm{Kg} / \mathrm{cm}^{2}$, para o cálculo da barra BJ procederemos do seguinte modo:

esbelteza : $\frac{1}{d}=\frac{225}{8}$, portanto, $>11$, desde que se fixe prèviamente, $d=8 \mathrm{~cm}$, para a menor dimensão da seção transversal.

Tratando-se de uma barra longa (trabalhando à compressão) empregaremos a fórmula III de Gordon, para se reduzir o coeficiente $\sigma=70 \mathrm{Kg} / \mathrm{cm}^{2}$, e destarte, prevenir-se contra a flambagem da mesma barra.

$$
o^{\prime}=70\left(1-\frac{1}{80 \mathrm{~d}}\right)=70\left(1-\frac{225}{80 \times 8}\right)=45 \mathrm{Kg} / \mathrm{cm}^{2}
$$

Em seguida entramos com êste valor na fórmula II : 


$$
\mathrm{P}=\sigma^{\prime} . \mathrm{S}, \text { sendo } \mathrm{S}=8 . \mathrm{x} .
$$

Logo, $5.040=45.8 x$

Donde $\mathrm{x}=14 \mathrm{~cm}$.

E, por conseguinte, a seção transversal mínima exigida pela barra será :

$$
\mathrm{S}=8 \times 14=112 \mathrm{~cm}^{2}
$$

Comercialmente, escolheriamos a bitola $16 \times 8 \mathrm{~cm}$ para a barra BJ.

Para a barra JI, que trabalha à tração, empregaremos a fórmula (I) :

$$
\begin{aligned}
& \mathrm{P}=\sigma \times \mathrm{S}, \text { ou } 4.500=70 \times \mathrm{S} \\
& \text { donde } \mathrm{S}=\frac{4.500}{70} \simeq 64 \mathrm{~cm}^{2}
\end{aligned}
$$

Repetindo para esta barra a bitola da asna, isto é, $16 \times 8$, para efeito de sambladura asna-arrochante, verifica-se que o arrochante (barra JI) assim estará trabalhando com bastante folga, pois que o mesmo exige apenas uma seç̧ão de $64 \mathrm{~cm}^{2}$.

$\mathrm{E}$, assim, com cálculos dessa natureza estudaremos as seções de quaisquer outras barras da tesoura, completando o quadro de esforços.

\subsection{Cálculo dos caibros:}

Os caibros recebem a carga das ripas (pêso das telhas, neve, etc.) e se apoiam sôbre as terças, com inclinação igual à da asna da tesoura. São, pois, vigas contínuas sôbre vários apôios, mas, para a simplicidade de cálculo, se considera o caibro dividido em diversas partes que ficam compreendidas entre duas terças, ou seja, como se fosse uma viga simples apoiada em suas extremidades (terças) e carregada uniformemente à razão de $\mathrm{p} \mathrm{Kg} / \mathrm{ml}$ ( $\mathrm{Kg}$ por metro linear), com vão $l$ igual à sua projeção horizontal. De acôrdo com esta hipótese, o momento fletor se calcula pela fórmula: 


$$
\mathrm{M}_{\max .}=\frac{\mathrm{pl}^{2}}{8}
$$

Em seguida entra-se com o valor dêsse momento fletor na fórmula da flexão:

$$
\frac{\mathrm{M}}{\sigma}=\frac{\mathrm{I}}{\mathrm{V}} \text { ou } \frac{\mathrm{M}}{\sigma}=\frac{\mathrm{bh}^{2}}{6} \text { para uma viga de seção re- }
$$

tangular, na qual

$\mathrm{b}=$ base

$\mathrm{h}=$ altura

Calculemos, por exemplo, um caibro para os dados seguintes :

Carga Total $=100 \mathrm{Kg} / \mathrm{m}^{2}$ (telhas, pressão do vento, etc.) espaçamento das terças $=2,25 \mathrm{~m}$

espaçamento dos caibros $=0,50 \mathrm{~m}$

inclinação do telhado $\alpha=26^{\circ} 34^{\prime}$ (ponto $=1 / 4$ )

A carga sôbre o comprimento de caibro entre terças será:

$2,25 \times 0,5 \times 100=112,50 \mathrm{Kg}, \quad$ sendo

$2,25 \times 0,50=1,125 \mathrm{~m}^{2}$ a superfície de carga.

O vão ou distância horizontal entre os dois apôios (terças) será :

$$
l^{\prime}=l \cos \alpha=2,25 \times \cos 26^{\circ} 34^{\prime}=2,0 \mathrm{~m}
$$

Para o momento fletor máximo teremos:

$$
\mathrm{M}=\frac{\mathrm{pl}^{2}}{8}=\frac{56,25 \times \overline{2,0}^{2}}{8}=28,13 \mathrm{Kg} \mathrm{m} \mathrm{ou} 2813 \mathrm{Kg} \mathrm{cm}
$$

Sendo $\sigma=70 \mathrm{Kg} / \mathrm{cm}^{2}$ o coeficiente de trabalho da peroba, obtem-se com a fórmula da flexão: 


$$
\begin{aligned}
\frac{\mathrm{M}}{\sigma} & =\frac{\mathrm{bh}^{2}}{6} \text { ou, para } \mathrm{b}=5 \mathrm{~cm}, \frac{2813}{70}=\frac{5 \mathrm{~h}^{2}}{6} \\
\text { donde } \mathrm{h} & =\sqrt{\frac{6 \times 2813}{70 \times 5}}=\sqrt{48} \cong 7 \mathrm{~cm}
\end{aligned}
$$

e, portanto, a bitola do caibro será de $5 \times 7 \mathrm{~cm}$.

\subsection{Cálculo das terças :}

Consideramos uma terça como uma viga simples, apoiada em suas extremidades sôbre as asnas das tesouras, cuja carga é aquela proveniente dos caibros, como se fosse uniformemente distribuida em seu comprimento $l$ (correspondente ao espaçamento de tesouras), à razão de $p \mathrm{Kg}$ por metro linear. Logo, para o cálculo do momento fletor usariamos, também, $M=\frac{\mathrm{pl}^{2}}{8}$

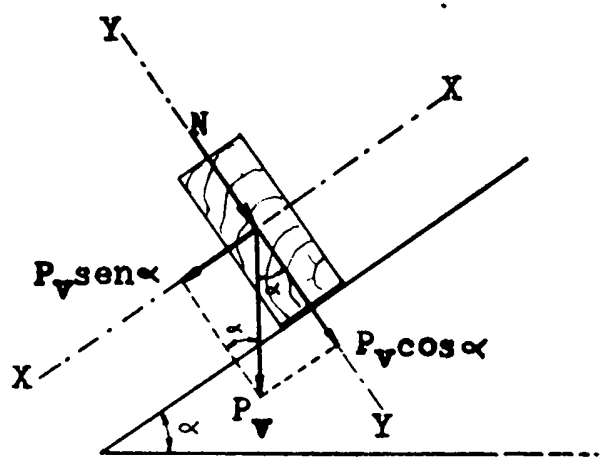

Fig. 5

As terças, todavia, se acham submetidas à flexão assimétrica (3), porque, em geral, elas são apoiadas face a face (que contém a menor dimensão da seção transversal) sôbre as asnas das tesouras (Fig. 5), de sorte que haverá sempre duas flexões : uma que flexiona a viga no plano do eixo YY e a outra, num plano XX normal ao anterior. Admitindo-se que as cargas atuem no sentido do eixo YY da terça, obtem-se :

$$
\text { py }=(\mathrm{N}+\mathrm{pv} \cdot \cos \boldsymbol{\alpha}) \text {. e }
$$


sendo

$\mathrm{N}=$ pressão do vento, normal ao telhado

$\mathrm{e}=$ espaçamento das terças

Se as cargas atuarem no sentido do eixo $\mathrm{XX}$ tiraremos:

$\mathrm{px}=\mathrm{pv}$. $\operatorname{sen} a \mathrm{x}$ e

Os momentos produzidos por estas cargas serão :

$$
\begin{gathered}
\mathrm{Mx}=\frac{\mathrm{py} \cdot \mathrm{l}^{2}}{8}=\frac{1}{8}(\mathrm{~N}+\mathrm{pv} \cdot \cos \alpha) \text { e } 1^{2} \\
\mathrm{My}=\frac{\mathrm{px} \cdot \mathrm{l}^{2}}{8}=\frac{1}{8} \mathrm{pv} \text { sen } \alpha \cdot \text { e. } \mathrm{l}^{2}
\end{gathered}
$$

da fórmula da flexão podemos tirar :

$\sigma=\frac{\mathrm{M}}{\frac{\mathrm{I}}{\mathrm{V}}}$ ou $\sigma=\frac{\mathrm{M}}{\mathrm{W}}$, sendo $\mathrm{W}=\frac{\mathrm{I}}{\mathrm{V}}$ (momentos resistentes)

Das flexões relativas aos dois eixos principais $\mathrm{XX}$ e $\mathrm{YY}$ obtemos a tensão máxima :

$$
\sigma=\sigma \mathrm{x}+\sigma \mathrm{y}=\frac{\mathrm{Mx}}{\mathrm{Wx}}+\frac{\mathrm{My}}{\mathrm{Wy}}
$$

Para as inclinações usuais, em geral, o momento fletor em relação ao eixo YY, é bem menor que o correspondente ao eixo XX.

2.4. Cálculo da emenda de peças de madeira para o arrochante

No comércio, em geral, o comprimento de vigotas não vai além de 5 ou 6 metros. Quando o vão da tesoura ultrapassa essa dimensão, somos forçados a emendar vigotas, a fim de constituir as diversas barras da tesoura, sobretudo o arrochante e as asnas, cujos comprimentos são, em relação aos das demais barras, os mais alterados para qualquer variação do vão. 
A emenda das barras da asna não demanda de cálculo, portanto as peças aí se unem naturalmente, topo a topo, devido à tensão de compressão à qual tôda a asna se acha submetida; os parafusos e chapas metálicas, nêste caso, servem apenas para dar rigidês à emenda (5).

O problema que vamos analisar agora, aliás, o mais simples, consiste em se unir duas peças de madeira (vigotas) de seção transversal retangular conhecida $(S=b h)$, topo a topo, por meio de parafusos (de diâmetro $d$ ) dispostos em linha e chapas metálicas (de espessura $e$ ), tal como se apresenta na Fig. 6, para resistirem à fórça axial de tração $P$.

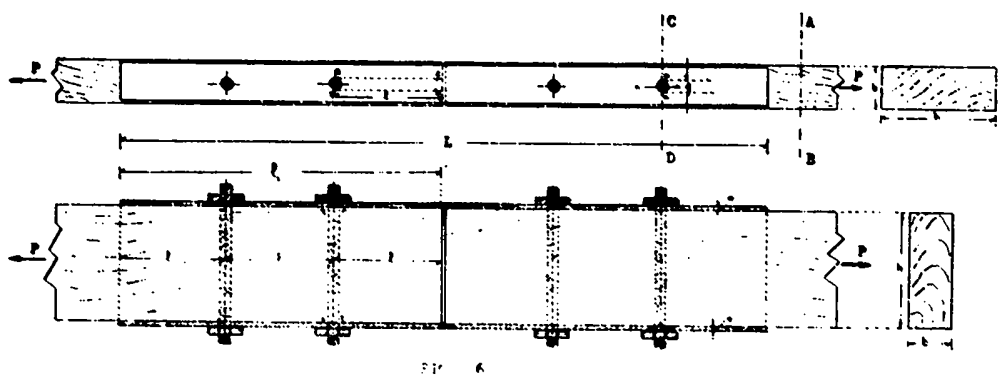

Fig. 6

A fôrça $P$ é transmitida de uma peça à outra por intermédio dos parafusos, os quais, deverão ter um diâmetro suficiente para a segurança da emenda, isto é, para que esta não se rompa, devido ao cisalhamento ao longo das seções transversais dos parafusos. A questão, assim analisada, resulta da consideração simplificada dos problemas de cisalhamento, porque supomos o cisalhamento distribuido em tensões uniformes nas seções transversais dos parafusos, muito embora, estudos mais rigorosos indiquem que essas tensões não se distribuem uniformemente e que os parafusos sofram não sòmente cisalhamento mas também flexão, sob à ação das fôrças $P$ de tração que, não agindo num mesmo plano vão produzir momentos (12). 6) é

$A$ tensão de tração numa seção $\mathrm{AB}$, fora da emenda (Fig.

$$
\sigma=\frac{\mathrm{P}}{\mathrm{S}}=\frac{\mathrm{P}}{\mathrm{bh}}
$$


$\mathrm{Na}$ seção $\mathrm{CD}$ a área útil da seção transversal da peça é $(b-d) h$, para a qual se calcula a tensão média de tração, aplicando

$$
\sigma^{\prime}=\frac{P}{(b-d) h}
$$

Nessa mesma seção $C D$, todavia, as tensões não se distribuem uniformemente; a tensão nos pontos $m$ é de duas a três vezes (11) o valor da tensão na seção $A B$, cujo valor podemos representar por

$$
\sigma^{\prime \prime}-\mathrm{K} \sigma
$$

sendo $K$ um coeficiente que depende da dimensão $b$ da peça e do diâmetro $d$ do parafuso. A experiência tem demonstrado que na seção $C D$, onde se verifica a região de tensão muito grande, o material se deforma quando a tensão atinge o valor correspondente ao limite de escoamento dêsse material. Este fato implica uma nova distribuição de tensões que nos permite considerá-la, pràticamente uniforme. Nos pontos $n$, diametralmente opostos, a fôrça aplicada se transmite da peça para o parafuso de modo a produzir tensões de compressão.

Como vemos, a análise das tensões, para as emendas de peças, com chapas, parafusos e porcas, se torna complicada, entretanto pode ser simplificada, com relativa aproximação, perfeitamente tolerável na prática, desprezando-se tanto as fôrças de tração e de atrito nos parafusos (difíceis de serem avaliadas) como as de atrito entre chapas e madeira, entre porcas e chapas e, por outro lado, admitindo-se que as tensões de cisalhamento se distribuem uniformemente ao longo das seções transversais $q r$ e st dos parafusos, nos planos de contacto das chapas metálicas com a peça de madeira (Fig. 6).

Nessas condições, a tensão de cisalhamento $\delta p$ é obtida, dividindo-se a fôrça $P$ de tração pela soma das áreas das seções transversais $q r$ e st dos parafusos:

$$
\delta \mathrm{p}=\ldots \frac{\mathrm{P}}{\mathrm{n} \pi \mathrm{d}^{2}}=\frac{\mathrm{d}}{\mathrm{n} \mathrm{d}^{2}}
$$


sendo $n$ o número de parafusos em cada uma das peças da emenda. Isto porque o parafuso de cisalhamento duplo equivale, sob o ponto de vista da resistência ao cisalhamento, a um parafuso de cisalhamento simples e seção dupla (9).

De um modo geral, empregando a nomenclatura usual, podemos nos utilisar dos dados seguintes (2) para a resolução dos casos mais simples que se apresentam na prática:

$\overline{\sigma f}=1.200 \mathrm{Kg} / \mathrm{cm}^{2}$ (tensão admissível de tração para o aço) $\bar{\sigma} \mathrm{m}=60 \mathrm{Kg} / \mathrm{cm}^{2}$ (tensão admissível de tração, no sentido paralelo às fibras, para a madeira)

$\overline{\delta f}=\begin{aligned} & 500-800 \mathrm{Kg} / \mathrm{cm}^{2} \text { (tensão admissivel de cisalhamento } \\ & \text { para o aço) }\end{aligned}$ $\bar{\delta}_{\mathrm{m}}=10-15 \mathrm{Kg} / \mathrm{cm}^{2}$ (tensão admissível de cisalhamento, no sentido paralelo às fibras, para a madeira) .

$E^{\prime}$ obvio que se deve obter com as expressões (II) e (I) $\delta \mathrm{p}<\bar{\delta} \mathrm{f}$ e $\boldsymbol{o}^{\prime}<\bar{\sigma} \mathrm{m}$, respectivamente. Em vista disso, calcula-se, fàcilmente, o diâmetro máximo admissível aos parafusos, em função da seção útil da madeira, aplicando-se :

$$
\bar{\sigma} \mathrm{m}=\frac{\mathrm{P}}{(\mathrm{b}-\mathrm{d}) \mathrm{h}}, \text { donde }
$$

$$
\mathrm{d}=\mathrm{b}--\frac{\mathrm{P}}{\bar{o} \mathrm{~m} h}
$$

Em seguida, o número de parafusos, em cada peça da emenda, se calculará com a fórmula seguinte, deduzida da expressão (II) :

$$
\mathrm{n}=\frac{2 \mathrm{P}}{\overline{\delta \mathrm{f}} \pi \mathrm{d}^{2}}
$$


Além da tensão de tração existem, também, tanto na madeira como nas chapas de aderência, tensões de cisalhamento nos planos ef e gh (Fig. 6) que devem ser calculadas.

$\mathrm{Na}$ madeira, essas tensões são de sentido paralelo às fibras, para uma seção resistente ao cisalhamento igual a $1 \times \mathrm{h}$, sendo $l$ a distância entre os pontos $e$ e $f$, ou, a distância eixo a eixo dos parafusos. Logo, para um número $n$ de parafusos, a seção total resistente será $2 \mathrm{nlh}$, e, então

$$
\bar{\delta}_{\mathrm{m}}=-\frac{\mathrm{P}}{2 \mathrm{nlh}} \text {, donde, } \mathrm{l}=\frac{\mathrm{P}}{2 \overline{\mathrm{mnh}}}
$$

Da mesma forma, nas chapas metálicas, essas tensões de cisalhamento $\delta$ c se calculam por

$$
\delta c=\frac{\mathrm{P}}{4 \mathrm{n} 1 \mathrm{e}}
$$

(VI), sendo e a espessura das chapas,

na condição de obter-se $\delta c<\overline{\partial f}$. Logo, a espessura das chapas necessária para resistir a tensão de cisalhamento se calculará pela fórmula:

$$
\mathrm{e}=\frac{\mathrm{P}}{4 \mathrm{n} 1 \overline{\delta f}}
$$

Por outro lado, essas chapas deverão resistir, também, à tensão de tração. Sendo b1 a largura das chapas (em geral, equivalente a $b$, menor dimensão da seção transversal das peças da emenda) e aplicando

$\mathrm{P}=\bar{\sigma} \mathrm{f} \times \mathrm{Sf}$, onde Sf é a seção transversal útil das chapas metálicas, obtem-se, pois,

$$
\mathrm{P}=\overline{\text { ff }} \times 2(\mathrm{~b} 1-\mathrm{d}) \mathrm{e}, \text { donde }
$$




$$
\mathrm{e}=\frac{\mathrm{P}}{2(\mathrm{~b} 1-\mathrm{d}) \bar{\sigma} \mathrm{f}}
$$

Dos valores encontrados para a espessura $e$ das chapas, com as fórmulas (VII) e (VIII), escolhe-se o maior dêles.

Calculamos, finalmente, o comprimento total $\mathrm{L}=2 \mathrm{l}_{1}$ da emenda (Fig. 6), pois que, com a fórmula (V) já conhecemos 1 , e como $l_{1}=(n+1) 1$, então, $L=2(n+1) 1$ (IX), que corresponde, também, ao comprimento que se deve tomar para as chapas metálicas de aderência.

Exemplo: (Fig. 7) - Calcular a emenda com parafusos e chapas metálicas, de duas peças de madeira (seção transversal retangular de $16 \times 6 \mathrm{~cm}$ ), para o arrochante de uma tesoura, submetido à tração de $4.500 \mathrm{Kg}$, sendo $\delta \mathrm{m}=10 \mathrm{Kg} / \mathrm{cm}^{2}$; $\bar{\sigma} \mathrm{m}=60 \mathrm{Kg} / \mathrm{cm}^{2} ; \bar{\delta} \mathrm{f}=800 \mathrm{Kg} / \mathrm{cm}^{2}$ e $\overline{o f}=1.200 \mathrm{Kg} / \mathrm{cm}^{2}$.

Solução :

Com a fórmula (III), calculamos o diâmetro máximo admissível aos parafusos :

$$
\mathrm{d}=\mathrm{b}-\frac{\mathrm{P}}{\overline{\sigma \mathrm{m} \mathrm{h}}}=6-\frac{4.500}{60 \times 16}=1,31 \mathrm{~cm} .
$$

Suponhamos que adotaremos $\mathrm{d}=1 / 2^{\prime \prime}=1,27 \mathrm{~cm}$

Aplicando a fórmula (IV) obtemos o número de parafusos para cada peça da emenda :

$$
\mathrm{n}=\frac{2 \mathrm{P}}{\overline{\partial f} \pi \mathrm{d}}=\frac{2 \times 4.500}{800 \times 3,1416 \times(1,27)^{2}} \cong 2 \text { parafusos }
$$

Entrando-se com a fórmula (V) calculamos o espaçamento mínimo, eixo a eixo, dos parafusos:

$$
l=\frac{\mathrm{P}}{2 \bar{\delta} \mathrm{m} \mathrm{nh}}=\frac{4.500}{2 \times 10 \times 2 \times 16}=7 \mathrm{~cm}, \text { ou, pràticamente, } 10 \mathrm{~cm} .
$$


A espessura $e$ das chapas, necessária para resistir apenas a tensão de cisalhamento se obtem com a fórmula (VII) :

$$
\mathrm{e}=\frac{\mathrm{P}}{4 \mathrm{n} 1 \overline{\delta \mathrm{f}}}=\frac{4.500}{4 \times 2 \times 10 \times 800} \cong 0,06 \mathrm{~cm},
$$

mas, com relação a resistência à tensão de tração, admitindo-se uma largura de 2" $(5,08 \mathrm{~cm})$ para as chapas metálicas (notese que $b=6 \mathrm{~cm}$ ) e aplicando-se a fórmula (VIII) resulta:

$$
\mathrm{e}=\frac{\mathrm{P}}{2(\mathrm{~b} 1-\mathrm{d}) \text { of }}=\frac{4.500}{2(5,08-1,27) 1.200} \cong 0,5 \mathrm{~cm}(5 \mathrm{~mm}) \text { ou, }
$$

pràticamente $1 / 4^{\prime \prime}$.

Esta será a esperssura a adotar-se às chapas metálicas.

O comprimento da emenda, ou, das chapas metálicas obtem-se com a fórmula (IX) :

$$
\mathrm{L}=2(\mathrm{n}+1) 1=2(2+1) 10=60 \mathrm{~cm} .
$$

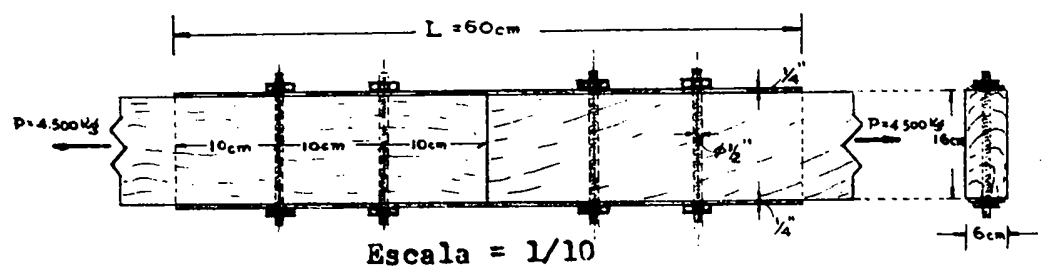

FIG. 7

\section{BIBLIOGRAFIA}

1. AlbUQUERQUE, AleXANDRE -- "Construções Civís", S. Paulo, 1942.

2. ASSOCIAÇÃO BRASILEIRA DE NORMAS TÉCNICAS -"Normas Recomendadas". Rio de Janeiro, 1947.

3. COBENO GONZALEZ, E. y CALLE RELLOSO, L. -- "Abacos para el calculo de Cerchas de Hierro Y Madera". Madrid, Dossat, 1951. 
4. GILLI, JOSE” ANGEL -- “Lecciones de Estática Gráfica”. Buenos Ayres, Hachette, 1944.

5. GIORDANO, G. -- "La Moderna Tecnica Delle Costruzioni In Legno". 2a. ed., Milano, Ulrico Hoepli, 1952.

6. GOLDENHORN, SIMON -- "Elementos de Estática Gráfica". 4a. ed. Buenos Aires, 1951.

7. MERRIMAN, THADDEUS, ed -- "American Civil Engineers Handbook”. New York, John Wiley, 1930.

8. PARKER, HARRY -- "Simplified Design of Roof Trusses for Architets and Builders". 1st ed. New York, John Wiley, 1945.

9. ROXO, AUGUSTO DE BRITO BELFORD -- "Lições de Resistência dos Materiais" 2a. ed. Rio de Janeiro, Francisco Alves, 1923.

10. SALLIGER, RUDOLF -- “Estática Aplicada”. Barcelona, Labor, 1950.

11. SILVA JUNIOR, JAYME FERREIRA DA -- "Estudo das Tensões". Escola Politécnica da Universidade de S. Paulo, 1949.

12. TIMOSHENKO, S. -- "Resistência dos Materiais". V. I, Rio de Janeiro, Publicações Pan-Americanas (p. 1945).

Apresentamos, a seguir, uma série de

PROJETOS DE TESOURAS DE MADEIRA (PEROBA)

calculadas para diferentes vãos. 

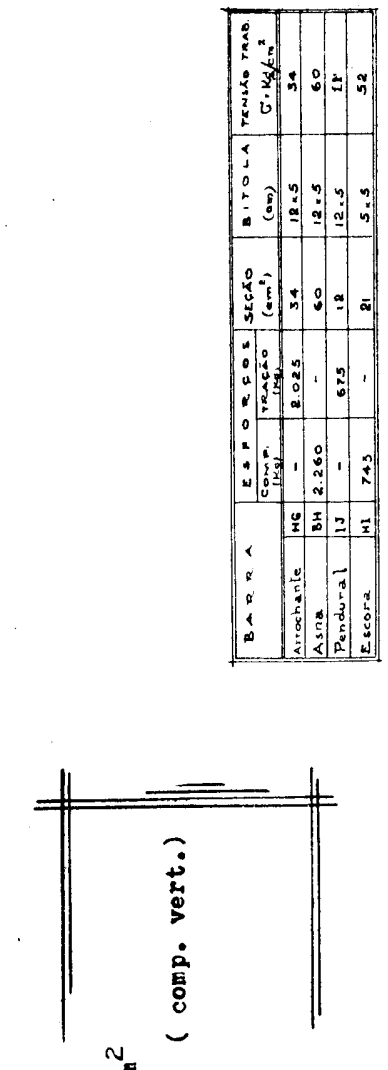
뵐

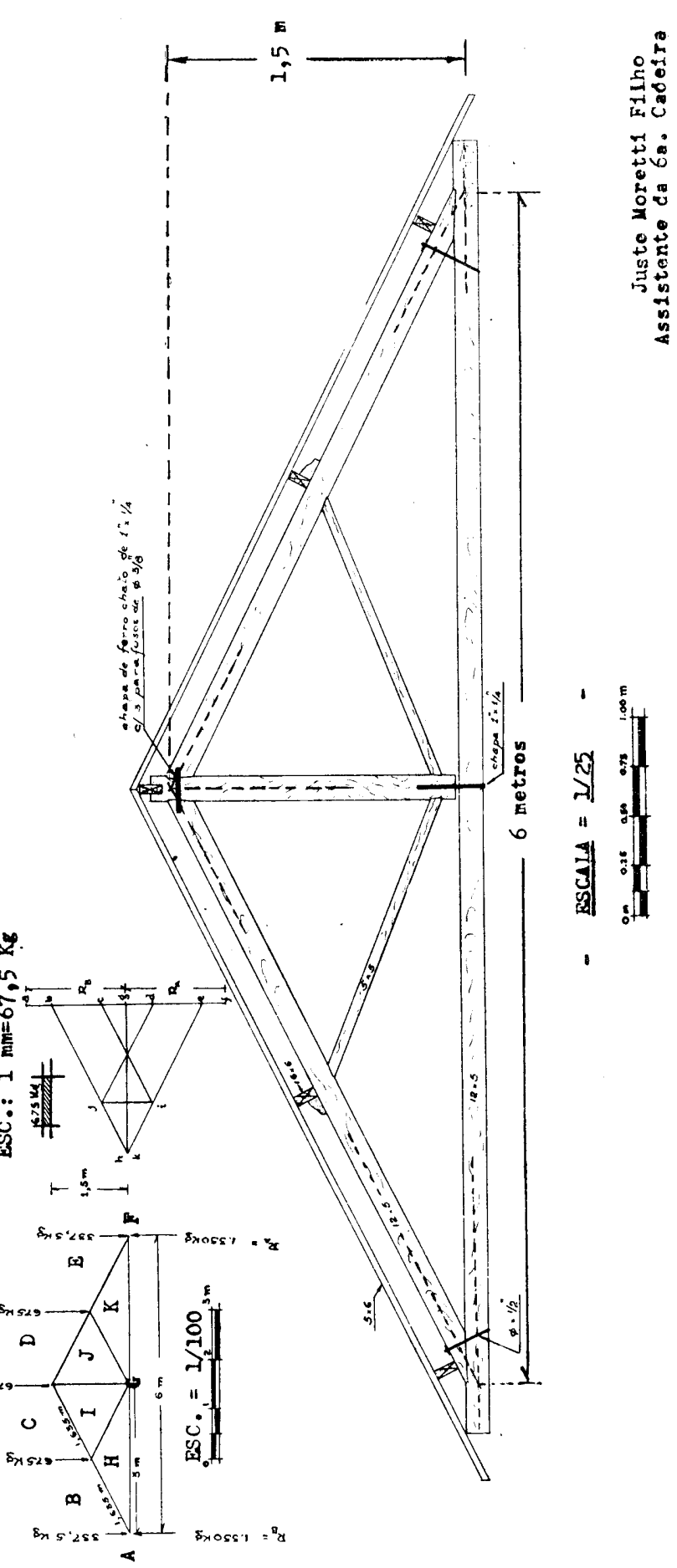





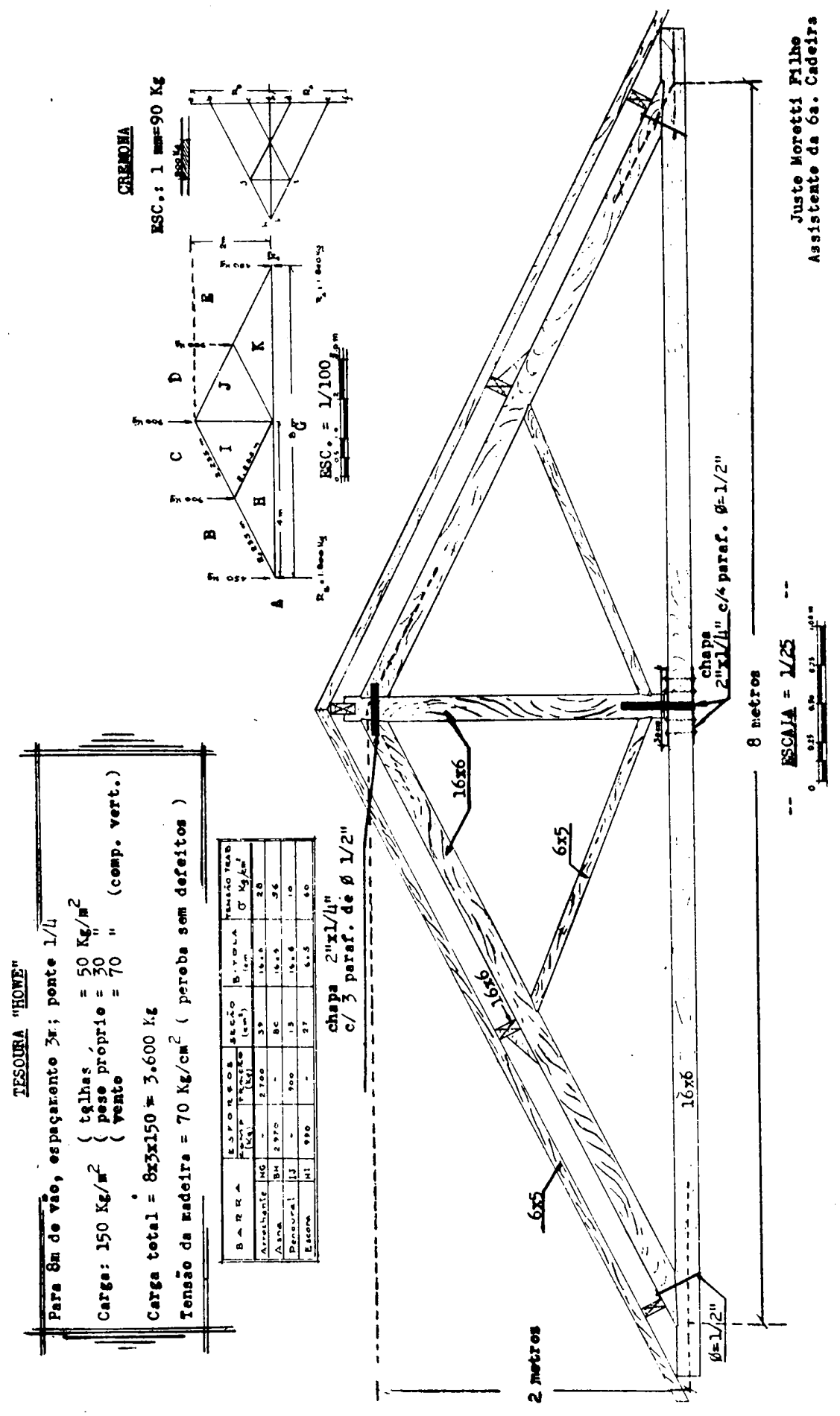





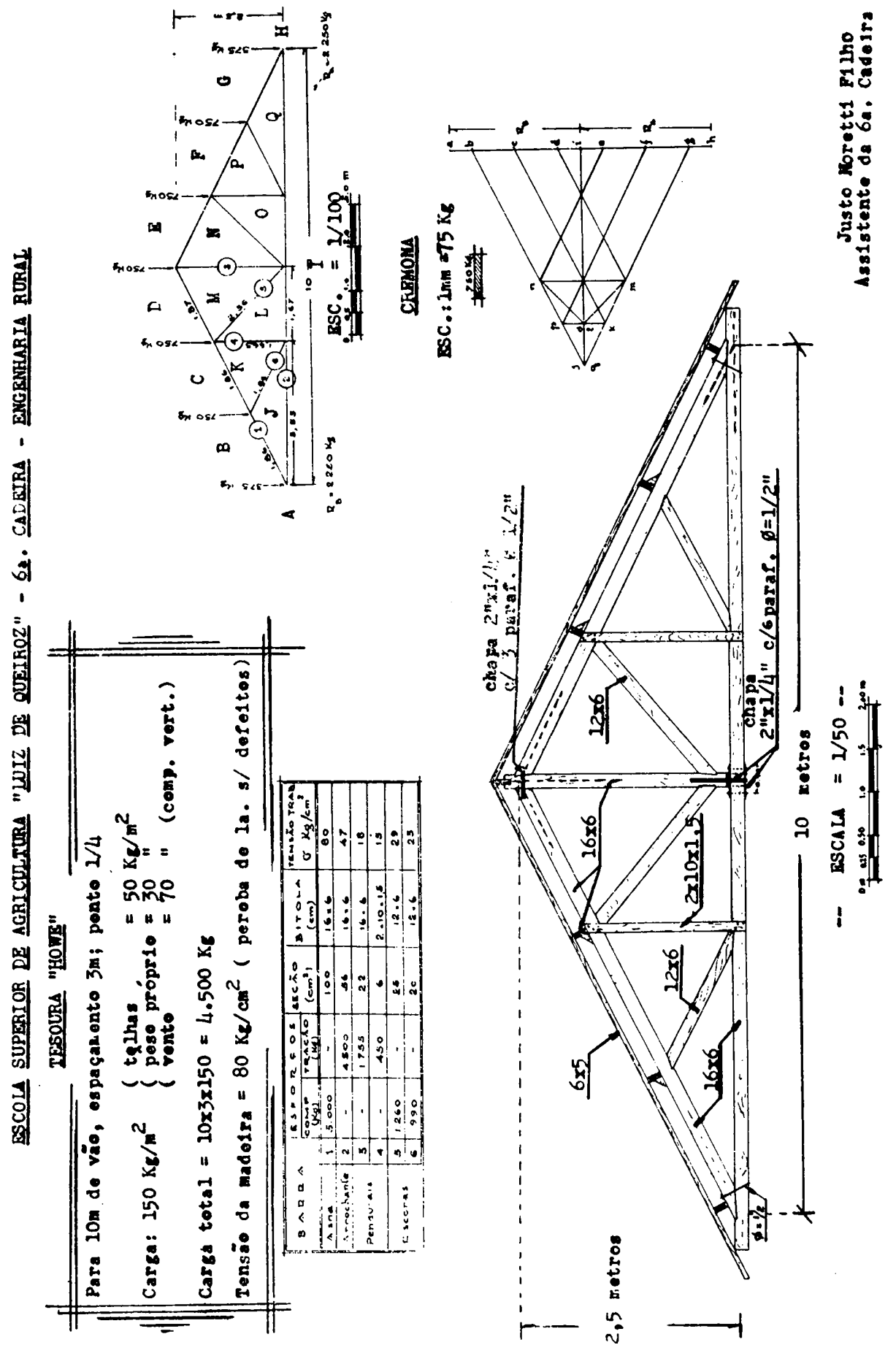




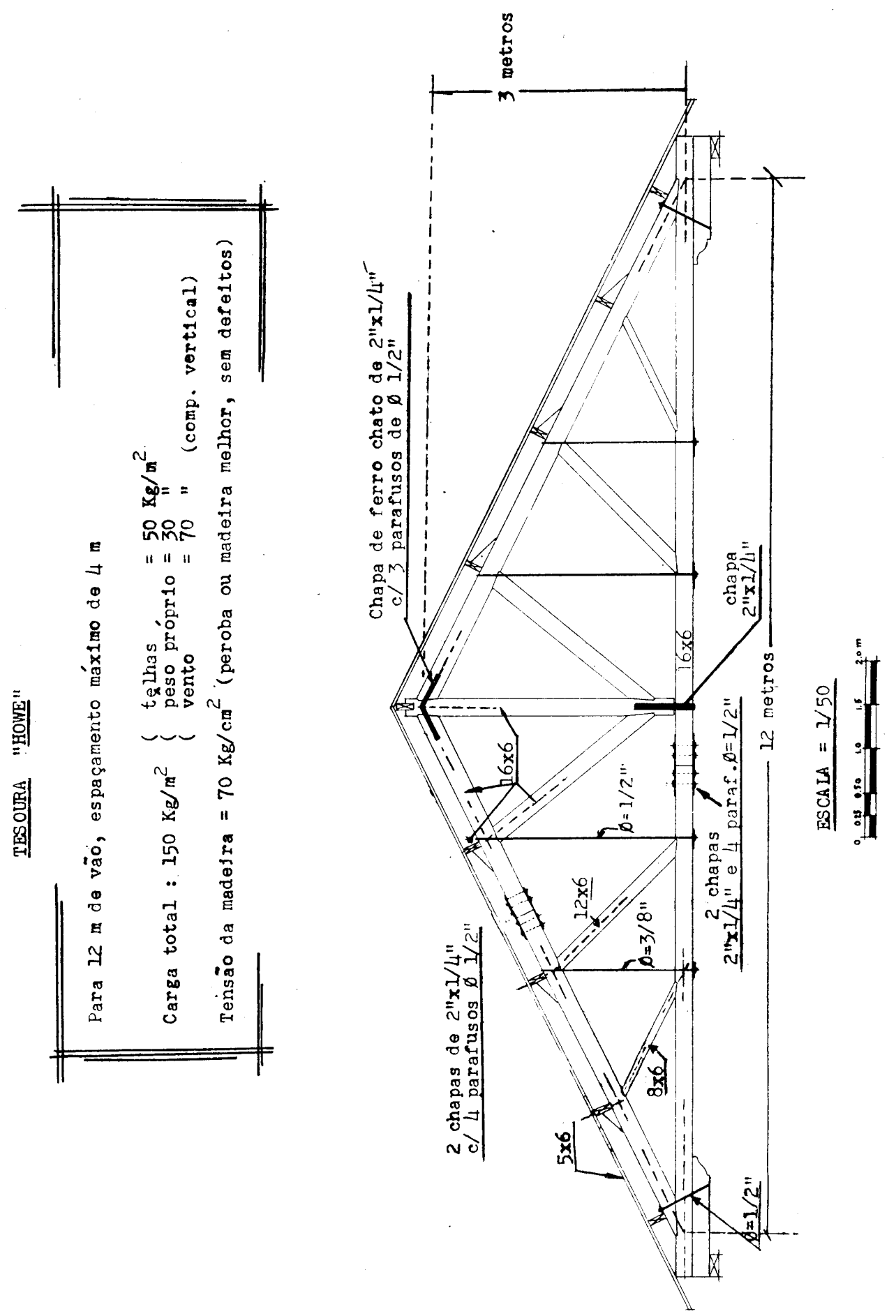


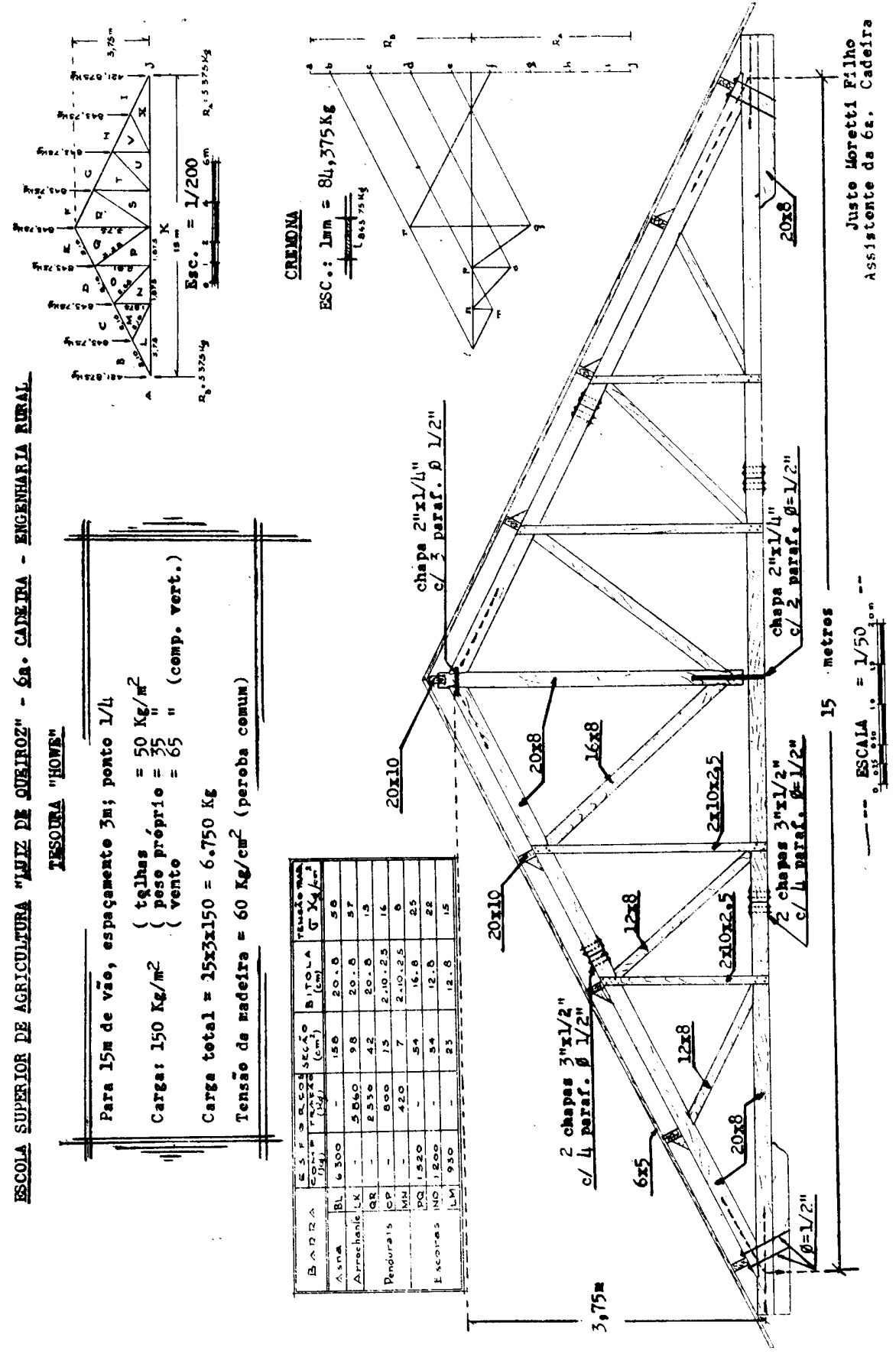


. 
projeto pe Treoura pare Coorrpura pos Armazens pa usina pa barra s/a" COBERT. DXI ETERNT

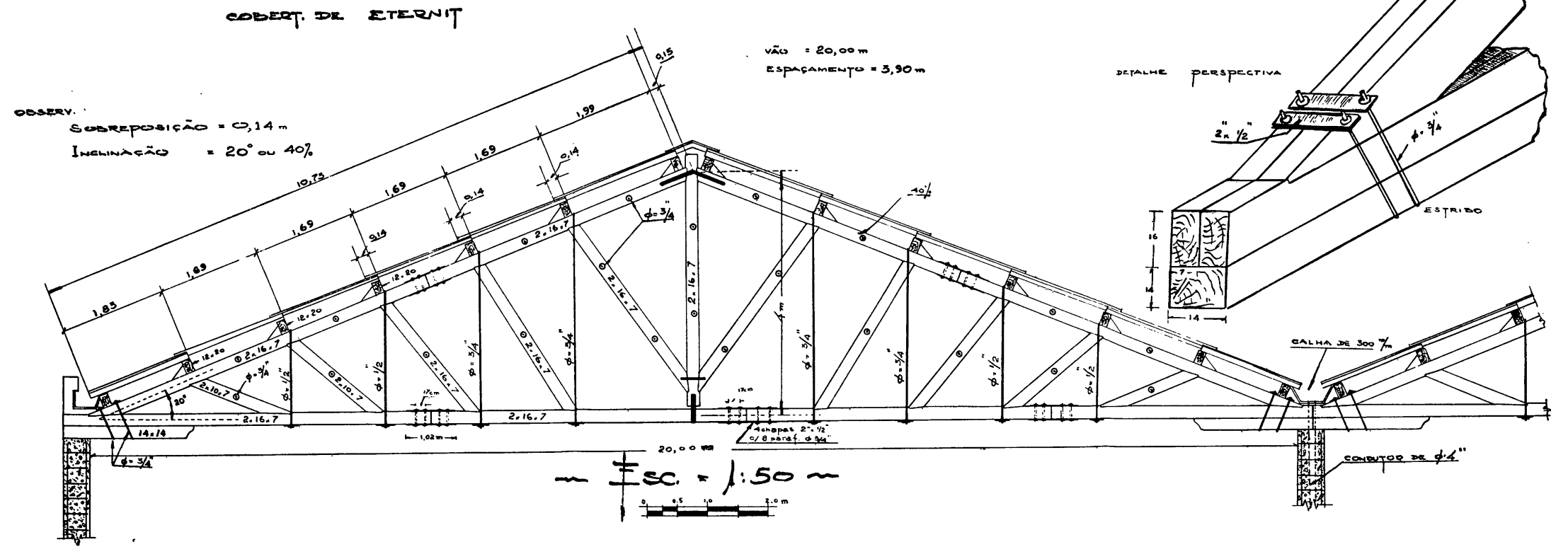




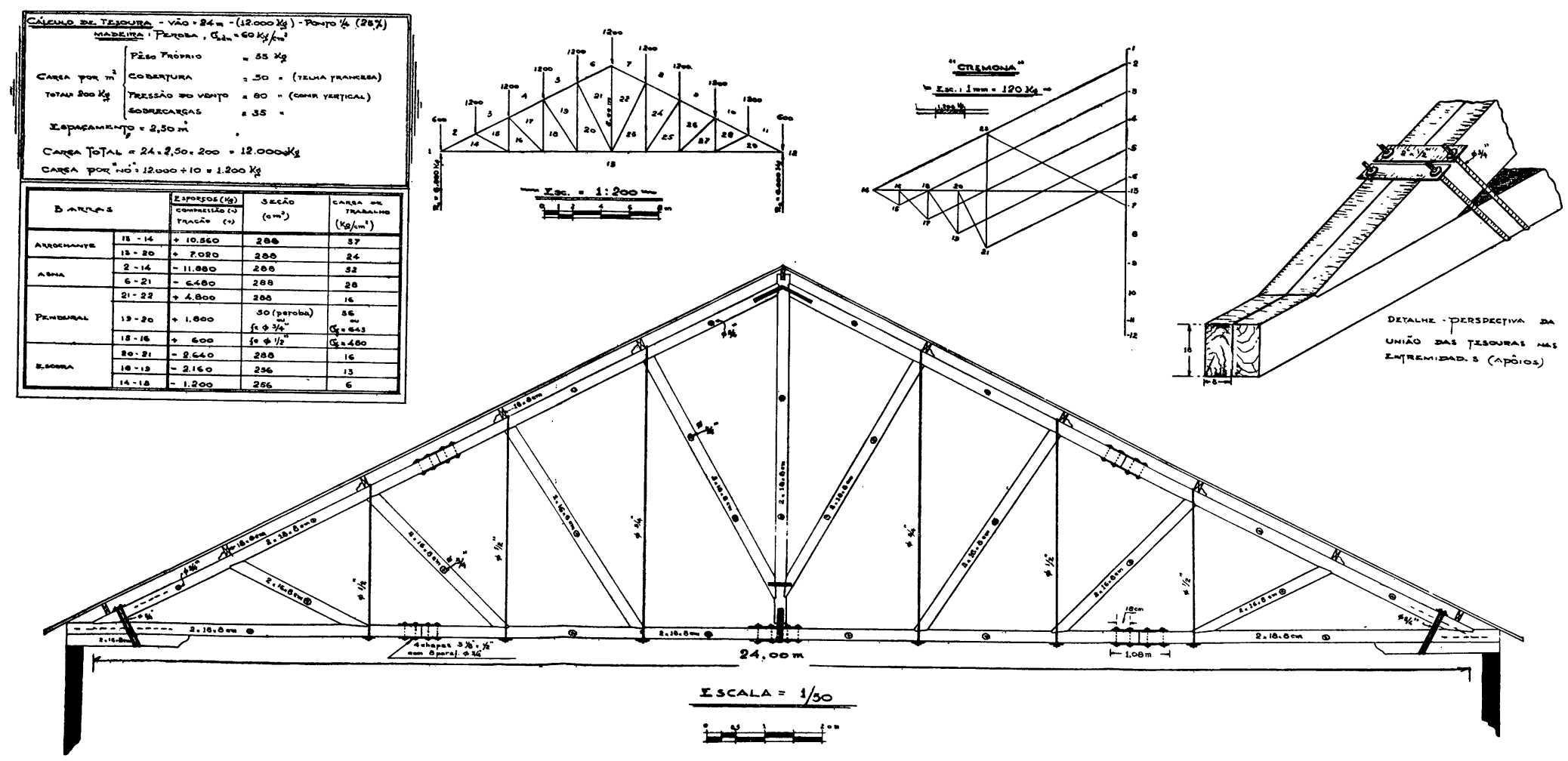

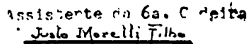

